\title{
Ipomoea Involcrata as an Ecofriendly Inhibitor for Aluminium in Alkaline Medium
}

\author{
I. B. Obot, ${ }^{1, *}$ N. O. Obi-Egbedi ${ }^{2}$ \\ ${ }^{1}$ Department of Chemistry, Faculty of Science, University of Uyo, Uyo, Nigeria \\ ${ }^{2}$ Department of Chemistry, University of Ibadan, Ibadan, Nigeria
}

Received March 2009; accepted 12 July 2009

\begin{abstract}
The corrosion inhibition of aluminium by Ipomoea involcrata (IP) in $1 \mathrm{M} \mathrm{NaOH}$ was rapidly assessed using the gasometric technique at 30 and $60{ }^{\circ} \mathrm{C}$. Results obtained showed that Ipomoea involcrata acts as an inhibitor for aluminium corrosion in $1 \mathrm{M}$ $\mathrm{NaOH}$. Inhibition efficiency increased with increase in concentration of IP up to $55.0 \%$ at $50 \mathrm{v} / \mathrm{v} \%$ and decreased with increase in temperature. The adsorption of IP was in accord with Langmuir adsorption isotherm at the studied temperatures. A mechanism of physical adsorption is proposed from the calculated values of $E_{a}, Q_{a d s}$ and $\Delta G_{a d s}$.
\end{abstract}

Keywords: Ipomoea involcrata, aluminium, corrosion inhibition, adsorption isotherm, thermodynamics.

\section{Introduction}

The continuous use of organic and inorganic inhibitors to secure metals against corrosion has come under severe criticism. Although some of them have proved to have excellent inhibiting abilities, their toxic nature, eco-unfriendliness and high cost have been cited as reasons for the major setback [1]. Research activities in recent times are geared towards finding alternative inhibitors to replace the organic and inorganic compounds.

Naturally occurring substances of both plant and animal origin which are readily available, cheap, renewable, ecofriendly and ecologically acceptable, have been successfully used as a replacement for the organic and inorganic inhibitors [2-5]. Plant products are organic in nature and some of the constituents, including tannins, organic acids, amino acids, alkaloids and pigments, are known to exhibit inhibiting actions [6]. Alkaloids such as papaverine, strychnine, quinine and nicotine, were studied as corrosion inhibitors in acidic medium [7]. Plant

\footnotetext{
* Corresponding author. E-mail address: proffoime@yahoo.com
} 
materials tested in our laboratory to date include Dacroydes edulis [8], Pachylobus edulis [9], Vigna unguiculata [10], Gum arabic [11-13], and Raphia hookeri [14]. However, literatures reveal that not much work appears to have been done on the inhibition of aluminium in alkaline medium using naturally available plant extracts.

Ipomoea involcrata (Ip) (Family: Convolulaceae) is a common ornamental vine with heart shaped and bright white pink or purple flowers that has a long history of use in central to southern Mexico. The plant has been shown to contain mainly d-lysergic acid amide (LSA) (Fig. 1) and small amounts of other alkaloids, namely: chanoclavine, elymoclavine, ergometrine and d-isolysergic acid amide [15]. However, it has never been tested as corrosion inhibitor for aluminium in alkaline medium.

In our ongoing effort to develop environmentally benign corrosion inhibitors for metal corrosion, we report for the first time the inhibition of aluminium corrosion by the extracts from the leaves and stems of Ipomoea involcrata using gasometric technique at 30 and $60{ }^{\circ} \mathrm{C}$.

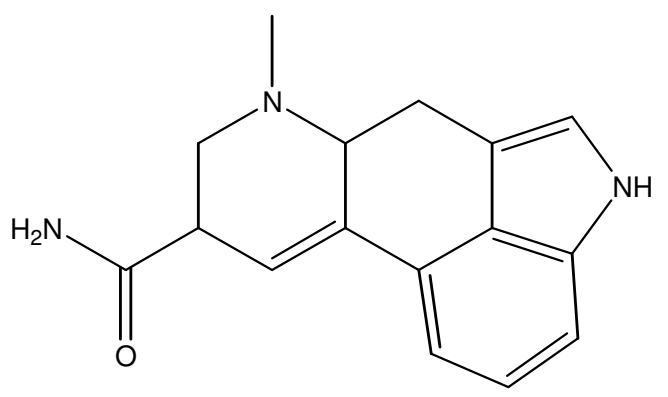

7-Methyl-4,6,6a,7,8,9-hexahydro-indolo[4,3-fg]quinoline-9-carboxamide

Figure 1. Chemical structure and name of d-lysergic acid amide.

\section{Experimental}

Aluminium sheets of the type AA 1060 and purity $98.8 \%$ were obtained from Sky Aluminium Ltd, Uyo, Nigeria, being of the same composition as those reported previously [8]. The test coupons were prepared, degreased and cleaned as previously described [9]. All chemicals used were of Analar grade. The procedure for the preparation of the IP extracts is similar to that reported recently by Okafor et al. [16]. Ipomoea involcrata were collected from Itak, Akwa Ibom State, Nigeria. They were dried in an N53C-Genlab Laboratory oven at $50{ }^{\circ} \mathrm{C}$, and ground to powder form. Ten grams of the powder were digested in $1 \mathrm{~L}$ of 1 $\mathrm{M} \mathrm{NaOH}$ solution. The resultant solution was kept for $24 \mathrm{~h}$, filtered and stored. From the stock solution, the leaves and stem extract test solutions were prepared at concentrations range of $10-50 \mathrm{v} / \mathrm{v} \%$.

The apparatus and procedure for gasometric determination of corrosion rates have earlier been reported in our previous publication [11]. The progress of the corrosion reaction was monitored by careful volumetric measurement of the evolved hydrogen gas at fixed time intervals. Experiments were conducted at 30 and $60{ }^{\circ} \mathrm{C}$. 


\section{Results and discussion}

\section{Corrosion rates and inhibition efficiency}

The relative rapidity and effectiveness of hydrogen evolution (gasometric) technique, as well as its suitability for monitoring in situ any perturbation by an inhibitor with respect to gas evolution in metal/corrodent systems have been established by earlier reports [17, 18]. Several authors have reported on comparable agreement between gasometric technique and other techniques of corrosion monitoring. These include polarization measurement [19], weight loss [20], and thermometric technique [21].

If it is assumed that corrosion occurs only at the free sites such that the covered sites have negligible corrosion rates, the inhibition efficiency $\% \mathrm{I}$ and hence the degree of surface coverage $(\theta)$ can be calculated as follows [22]:

$$
\begin{gathered}
\% I=\left(1-\frac{V_{H t}^{1}}{V_{H t}^{o}}\right) x 100 \\
\theta=1-\frac{V_{H t}^{1}}{V_{H t}^{o}}
\end{gathered}
$$

where $V_{H}^{1}$ is the volume of hydrogen evolved at time" t" for inhibited solution and $V_{H}^{O}$ that for unhibited solution.

The corrosion rate of aluminium was assessed by the $\mathrm{H}_{2}$ evolution rate in the absence and presence of different concentrations of IP at $30{ }^{\circ} \mathrm{C}$ (Fig. 2). Similar plots were obtained at $60{ }^{\circ} \mathrm{C}$ (not shown). A closer look at the figure reveals that the introduction of the plant extracts resulted in the reduction of the rate of $\mathrm{H}_{2}$ gas evolution as compared to the blank. Fig. 3 illustrates the variation of inhibition efficiency with concentration for the studied extracts of IP. The nonlinearity and non-uniformity of the plots suggest that the inhibition processes were heterogeneous and involved several steps. The plots indicate that \% I increased with concentration of the extracts but decreased with increase in temperature. This is attributed to the decrease in the protective nature of the inhibitive film formed on the metal surface (or desorption of the inhibitor molecules from the metal surface) at higher temperatures [22]. This suggests physical adsorption mechanism. Physical (electrostatic) adsorption takes place when inhibition efficiency decreases with increase in temperature (whereas chemical adsorption takes place when inhibition efficiency increases with increase in temperature [11]. The inhibitive action of the extracts is due mainly to the presence of d-lysergic acid amide and other alkaloids present in the plant extracts. These compounds contain heteroatoms such as oxygen, nitrogen and aromatic rings with $\pi$-bonds in their molecules, which serve as centers of adsorption onto the metal surface. Owing to the complex chemical composition of plant extracts, the presence of other phytochemical components of the extracts may not be ruled out in the adsorption process. 


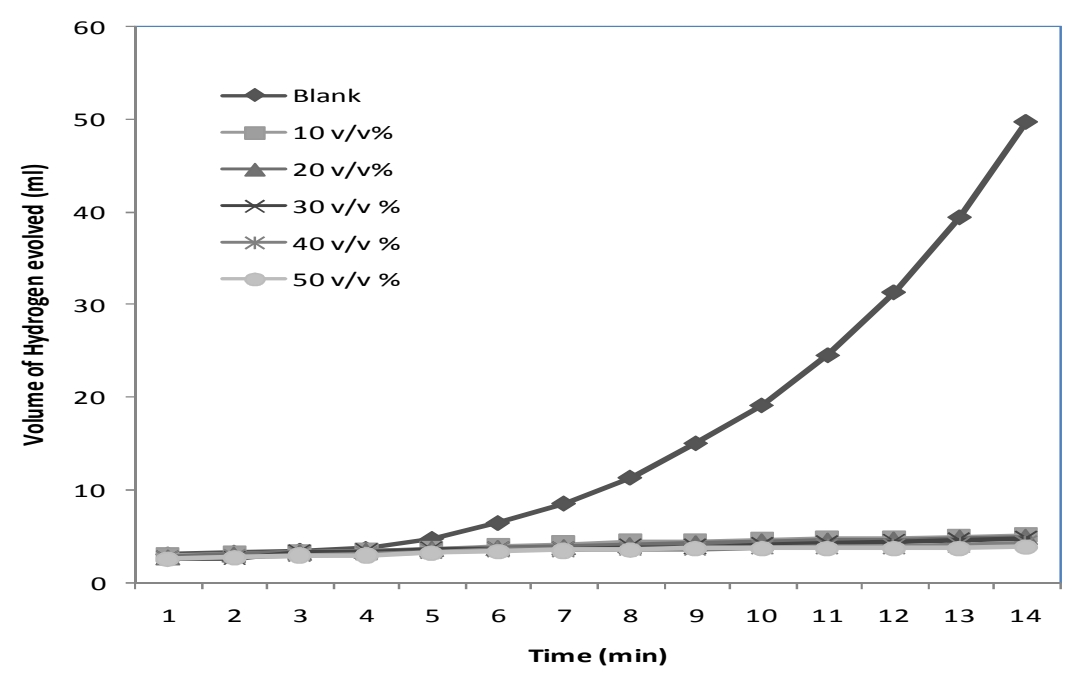

Figure 2. Plot of hydrogen evolution against time during aluminium corrosion in $1 \mathrm{M}$ $\mathrm{NaOH}$ in the absence and presence of different concentrations of Ipomoea involcrata extracts at $30{ }^{\circ} \mathrm{C}$.

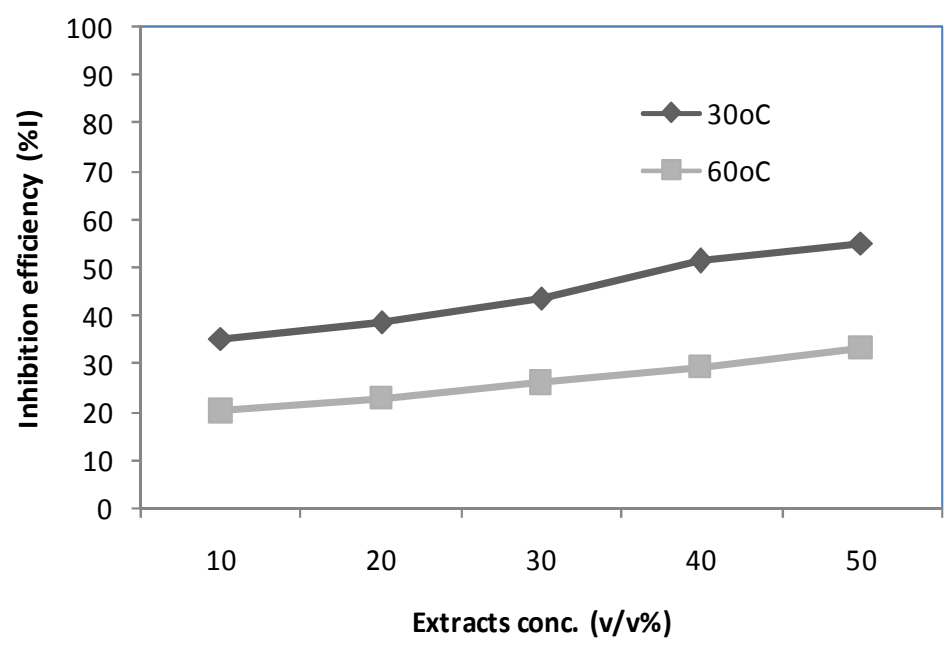

Figure 3. Plots of inhibition efficiency against concentration of Ipomoea involcrata at 30 and $60{ }^{\circ} \mathrm{C}$.

\section{Kinetic and adsorption consideration}

Thus in examining the effect of temperature on the corrosion process, the apparent activation energies $\left(E_{a}\right)$ were calculated from Arrhenius equation [22]:

$$
\log \frac{\rho_{2}}{\rho_{1}}=\frac{E_{a}}{2.303 R}\left(\frac{1}{T_{1}}-\frac{1}{T_{2}}\right)
$$

where $\rho_{2}$ and $\rho_{1}$ are the corrosion rates at temperatures $\mathrm{T}_{1}$ and $\mathrm{T}_{2}$, respectively, and $\mathrm{R}$ the molar gas constant. An estimate of heat of adsorption was obtained from the trend of surface coverage with temperature as follows [11]: 


$$
Q_{a d s}=2.303 R\left[\log \left(\frac{\theta_{2}}{1-\theta_{2}}\right)-\log \left(\frac{\theta_{1}}{1-\theta_{1}}\right)\right] x\left(\frac{T_{1 X} T_{2}}{T_{2}-T_{1}}\right)
$$

where $\theta_{1}$ and $\theta_{2}$ are the degrees of surface coverage at temperatures $\mathrm{T}_{1}$ and $\mathrm{T}_{2}$.

The average activation energy for the dissolution of aluminium in $1 \mathrm{M} \mathrm{NaOH}$ solution between 30 and $60{ }^{\circ} \mathrm{C}$ was found to be $32.11 \mathrm{~kJ} / \mathrm{mol}$. In the presence of the additives, the corrosion rate is decreased. This is evident in the increased value of the average activation energy $\left(E_{a}=40.30 \mathrm{~kJ} / \mathrm{mol}\right)$. Increased activation energy $\left(E_{a}\right)$ in inhibited solutions compared to the blank suggests that the inhibitor is physically adsorbed on the corroding metal surface [14]. The negative $\mathrm{Q}_{\mathrm{ads}}$ values ranging from $(-11.09$ to $-8.95 \mathrm{~kJ} / \mathrm{mol})$ indicate that the degree of surface coverage decreased with rise in temperature, supporting the earlier proposed physisorption mechanism [9].

It is a widely held view by many authors that the adsorption of organic inhibitor molecules is often a displacement reaction involving the removal of adsorbed water molecules from the metal surface $[14,21]$ :

$$
\operatorname{Org}_{(\mathrm{sol})}+x \mathrm{H}_{2} \mathrm{O}_{(\mathrm{ads})} \leftrightarrows \mathrm{Org}_{(\mathrm{ads})}+x \mathrm{H}_{2} \mathrm{O}_{(\mathrm{sol})}
$$

In general, the proceeding of physical adsorption requires the presence of both electrically charged surface of the metal and charged species in the bulk of the solution. Chemisorption process involves charge sharing or charge transfer from the inhibitor molecules to the metal surface to form a coordinate type of a bond. This is possible in case of a positive as well as a negative charge of the metal surface [10].

Perusal of literatures show that organic compounds act as an inhibitor by adsorption on the metal surface. Inhibitor molecules may adsorb on the aluminium surface in the form of:

(i) neutral molecule via chemisorption mechanism involving the sharing of electrons between the heteroatom and aluminium;

(ii) adsorption of inhibitor can occur through $\pi$-electron interactions between the aromatic ring of the molecule and the metal surface;

(iii) cationic form with positively charged part of the molecule oriented towards negatively charged aluminium surface [28]. Adsorption can also occur via electrostatic interaction between a negatively charged surface, which is provided with a specifically adsorbed anion on aluminium and positive charge of the inhibitor.

Important information about the interaction between Ipomoea involcrata extracts and the aluminium surface can be provided by the adsorption isotherm. In this regard, surface coverage values $(\theta)$ were calculated using equation (2). To ascertain the nature of adsorption, the surface coverage values for IP extracts for 30 and $60{ }^{\circ} \mathrm{C}$ were fitted into different adsorption isotherm models, and correlation coefficients $\left(\mathrm{R}^{2}\right)$ were used to determine best fit which was obtained with the Langmuir adsorption isotherm. The Langmuir isotherm is given by [23]: 


$$
\frac{C}{\theta}=\frac{1}{K_{a d s}}+C
$$

The strong correlation $\left(\mathrm{R}^{2} \geq 0.95\right)$ of the Langmuir adsorption was observed for the extracts at the two temperatures studied (Fig. 4). This isotherm postulates that there is no interaction between the adsorbed molecules and the energy of adsorption is independent on the surface coverage $(\theta)$. Langmuir's isotherm assumes that the solid surface contains a fixed number of adsorption sites and each holds one adsorbed species [24]. The slopes of the straight lines obtained from the plots of Langmuir isotherm for the extracts are more than unity (1.51 and 2.49). So, it could be concluded that there are more than one adsorption site on the aluminium surface. A modified Langmuir adsorption isotherm [25] could be applied to this phenomenon, which is given by the corrected equation:

$$
\frac{C}{\theta}=\frac{n}{K_{a d s}}+n C
$$

This is indicative of some divergence from pure monolayer adsorption and can be attributed to interactions between adsorbate species on the metal surface as well as changes in the adsorption heat with increasing surface coverage [26], factors which were not taken into consideration in derivation of the isotherm.

The free energy of adsorption $\Delta G_{a d s}^{o}$ of the inhibitors on aluminium surface can be determined using the following equation [27]:

$$
\Delta G_{a d s}^{o}=-R T \ln \left(K_{a d s} x 55.5\right)
$$

where $\Delta G_{a d g}^{\circ}$ is the standard free energy of adsorption, $K_{a d s}$ is the equilibrium constant of adsorption and the value of 55.5 is the concentration of water in solution expressed in $\mathrm{mol} \mathrm{L}^{-1}$.

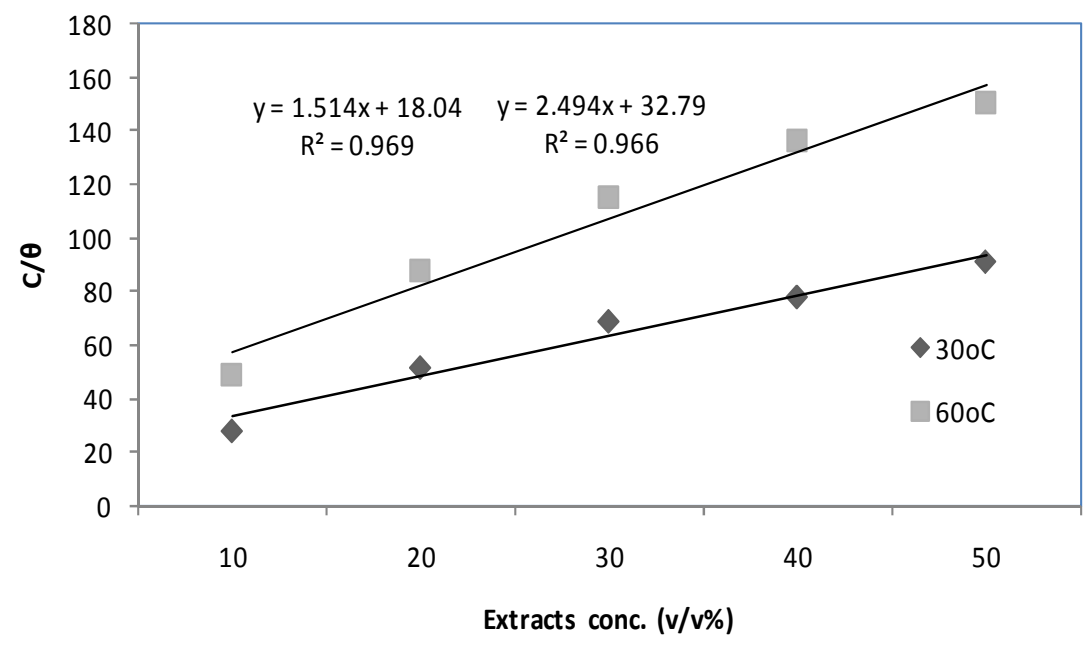

Figure 4. Langmuir adsorption plot for Ipomoea involcrata at 30 and $60{ }^{\circ} \mathrm{C}$. 
The values of $\Delta G_{a d s}^{o}$ obtained were $-2.83 \mathrm{~kJ} / \mathrm{mol}$ and $-1.46 \mathrm{~kJ} / \mathrm{mol}$ at 30 and 60 ${ }^{\circ} \mathrm{C}$, respectively. The negative values of $\Delta G_{a d s}^{o}$ at the two temperatures are all less than $-20 \mathrm{~kJ} / \mathrm{mol}$. This phenomenon indicates that the extracts from Ipomoea involcrata are spontaneously and strongly adsorbed onto the aluminium surface. Survey of literature reveals that negative values of $\Delta G_{a d s}^{o}$ around $-20 \mathrm{~kJ} / \mathrm{mol}$ or lower are consistent with electrostatic interaction between the charged molecules and the charged metal (physisorption) [27].

\section{Conclusions}

1. Ipomoea involcrata acts as inhibitor for aluminium in $1 \mathrm{M} \mathrm{NaOH}$ solution.

2. Inhibition efficiency increases with increase in extracts concentration and decreases with temperature.

3. The adsorption of extracts of IP follows the Langmuir adsorption isotherm.

4. The phenomenon of physical adsorption is proposed from the kinetic/thermodynamic parameters obtained.

\section{References}

1. K. Barouni, L. Bazzi, R. Salghi, M. Mihit, B. Hammouti, A. Albourine, S. El Issami, Matt. Lett. 62 (2008) 3325.

2. B. Bouyanzer, B. Hammouti, L. Majidi, Matt. Lett. 60 (2006) 2840.

3. S. Cheng, S. Chen, T. Liu, X. Chang, Y. Yin, Matt. Lett. 61 (2007) 3276.

4. $\quad$ O. Avwiri, F.O. Igho, Matt. Lett. 57 (2003) 3705.

5. $\quad$ K.O. Orubite, N.C. Oforka, Matt. Lett. 58 (2004) 1768.

6. E.E. Oguzie, Portugaliae Electrochimica Acta 26 (2008) 303.

7. G. Gunasekaran, L.R. Chauhan, Electrochimica Acta 49 (2004) 4387.

8. S.A. Umoren, I.B. Obot, E.E. Ebenso, N.O. Obi-Egbedi, Portugaliae Electrochimica Acta 26 (2008) 199.

9. S.A. Umoren, I.B. Obot, E.E. Ebenso, E-J. Chem. 5(2) (2008) 355.

10. S.A. Umoren, I.B. Obot, L.E. Akpabio, S.E. Etuk, Pigment \& Resin Technol. 37(2) (2008) 98.

11. S.A Umoren, I.B. Obot, E.E. Ebenso, P.C. Okafor, O. Ogbobe, E.E. Oguzie, Anti-Corros. Methods and Mater. 53(5) (2006) 277.

12. S.A. Umoren, O. Ogbobe, E.E. Ebenso, Trans. SAEST 41 (2006) 74.

13. S.A. Umoren, Cellulose 15 (2008) 751.

14. S.A. Umoren, I.B. Obot, N.O. Obi-Egbedi, Mater. Sci. 44(1) (2009) 274.

15. W. Powell, The Anarchist Cookbook, Orzack press, (2002) p.44.

16. P.C. Okafor, M.E. Ikpi, I.E. Uwah, E.E. Ebenso, U.J. Ekpe, S.A. Umoren, Corros. Sci. 50 (2008) 2310.

17. E.E. Oguzie, Corros. Sci. 49 (2007) 1527.

18. A.I. Onuchukwu, Mater. Chem. Phys. 20 (1988) 323.

19. A.Y. Eltre, Corros. Sci. 43 (2001) 1031. 
20. S.A. Umoren, E.E. Ebenso, P.C. Okafor, U.J. Ekpe, O. Ogbobe, J. Appl. Polymer Sci. 103 (2007) 2810.

21. S.A. Umoren, E.E. Ebenso, Mater. Chem. Phys. 106 (2007) 393.

22. I.B. Obot, N.O. Obi-Egbedi, S.A. Umoren, Corros. Sci. 51 (2009) 276.

23. S.A. Umoren, I.B. Obot, E.E. Ebenso, N.O. Obi-Egbedi, Int. J. Electrochem. Sci. 3 (2008) 1029.

24. E.E. Oguzie, Portugaliae Electrochimica Acta 26 (2008) 303.

25. S.A. Ali, M.T. Saeed, S.U. Rahman, Corros. Sci. 45 (2003) 253.

26. R.F.V. Villamil, P. Corio, J.C. Rubin, S.M.L. Agostinho, J. Electroanal. Chem. 472 (1999) 112.

27. I.B. Obot, N.O. Obi-Egbedi, Surface Review and Letters 15(6) (2008) 903.

28. I.B. Obot, N.O. Obi-Egbedi, Colloids and surfaces A: Physicochem.Eng. Aspects 330 (2008) 207. 